\title{
Características morfofisiológicas em plantas de Tabebuia heptaphyilla (vell.) tol. em condições de luminosidade
}

\author{
Susana Cristine SIEBENEICHLER ${ }^{1}$, Gilson Araújo de FREITAS², Rubens Ribeiro da SILVA ${ }^{3}$, \\ Gentil Cavalheiro ADORIAN ${ }^{4}$, Daniel CAPELLARI ${ }^{5}$
}

\section{RESUMO}

Um fator importante na determinação da sobrevivência de uma espécie, é sua adaptação à condição de alta ou baixa luminosidade. O objetivo deste estudo foi verificar o desenvolvimento inicial, teores de clorofila e alocação de biomassa em plantas de Tabebuia heptaphyilla (Vell.) Tol, em três condiçóes de luminosidade. O experimento foi conduzido em delineamento de blocos casualizados, com três níveis de luminosidade (pleno sol, 50\% de luz e sombra natural) e com 15 repetiçôes em cada tratamento, sendo cada planta considerada como uma repetição. Foram avaliados a altura e diâmetro aos 60, 82, 103, 124, 145 dias após a emergência das plântulas. Plantas expostas ao ambiente de sombra natural apresentaram menor desempenho vegetativo do que as demais condições de cultivo testadas ( $50 \%$ e $100 \%$ de luminosidade). A condição de $50 \%$ de luminosidade pode ser recomendada para a formação de mudas, no entanto, essa prática também pode ser realizada a pleno sol.

PALAVRAS-CHAVE: Área foliar específica, Ipê amarelo, alocação de biomassa, teor de clorofila.

\section{Morphophysiological characteristics in plants of Tabebuia heptaphyilla (vell.) tol., in conditions of luminosity.}

\begin{abstract}
Important factor in determining species survival, for example, its adaptability to high or low conditions of luminosity. The objective of this study was to verify the initial development, chlorophyll content, and biomass allocation in plants of Tabebuia heptaphyilla (vell.) tol., in three lighting conditions. The experiment was carried out in randomized complete blocks, with three levels of luminosity (full sunlight, $50 \%$ of light, and natural shade) and 15 repetitions of each treatment, and each plant considered as a repetition. The height and diameter were studied on $60,82,103,124,145$ days after the emergence of the plants. Plants exposed in the shade showed lower vegetation performance than the other conditions tested $(50 \%$ and $100 \%$ of RFA). The 50\% luminosity, as well as full sunlight, can be recommended for the formation of seedlings.
\end{abstract}

KEY WORDS: adaptability, lighting levels, foliar especific area.

\footnotetext{
1 Dra Produção Vegetal; Profa. Adjunta III-Curso de Agronomia; Laboratório de Ecofisiologia Vegetal- UFT/CAUG, susana@uft.edu.br

2 Eng. Agr. , Mestrando em Produção Vegetal- UFT/CAUG, araujo@hotmail.com

${ }^{3}$ MSc Solos e Nutrição de Plantas, Prof. Assistente III, Laboratório de Solos- UFT/CAUG, rrs2002@uft.edu.br

${ }^{4}$ Eng. Agr. , Mestrando em Produção Vegetal- UFT/CAUG, gentil.cav@uft.edu.br

${ }^{5}$ Eng. Agr. Empresa Pró-Flora Projetos e consultoria, Gurupi -TO, daniel@inforural.com.br
} 


\section{INTRODUÇÃO}

O Ipê é uma espécie utilizada para paisagismo, particularmente para arborização de ruas e avenidas, sendo ótima também para reflorestamentos mistos, destinados à recomposição de áreas degradadas de preservação permanente. É uma espécie arbórea da família Bignoniácea, que mede de 10-20 m de altura. Produz anualmente quantidade razoável de sementes, que são disseminadas pelo vento. O florescimento ocorre entre os meses de julho a setembro, com a planta totalmente despida de folhagem, ocorrendo frutificação nos meses de setembro até o início de outubro (Lorenzi, 2000).

A capacidade das mudas crescerem rapidamente, quando sombreadas, é um mecanismo importante de adaptação da espécie, sendo uma valiosa estratégia para escapar às condiçôes de baixa intensidade luminosa. Esta adaptação a baixas intensidades luminosas é ditada pelas características genéticas da planta em interação com o meio ambiente, fazendo com que as folhas apresentem anatomia e propriedades fisiológicas que as capacitam para o uso efetivo da radiação solar disponível (Morais Neto et al. 2000).

O crescimento e adaptação da planta a diferentes condiçốes luminosas do ambiente podem ser relacionados, à habilidade das plantas em ajustar, eficaz e rapidamente, seu comportamento fisiológico e fotossintético para maximizar a aquisição de recursos nesse ambiente (Dias filho, 1997). Plantas submetidas a condições luminosas têm a clorofila constantemente sintetizada e destruída (foto-oxidação), porém sob intensidades luminosas mais elevadas ocorre maior degradação, e o equilíbrio é estabelecido a uma concentração mais baixa. Portanto, folhas de sombra possuem concentração maior de clorofila do que folhas de sol (Larcher, 2000).

O presente trabalho teve como objetivo avaliar o desenvolvimento inicial, teores de clorofila e alocação de biomassa em plantas de Tabebuia heptaphyilla (Vell.) Tol, em três condiçôes de luminosidade, visando a produção de mudas.

\section{MATERIAL E MÉTODOS}

O presente estudo foi conduzido na área experimental da Universidade Federal de Tocantins (UFT), Campus Universitário de Gurupi, localizado na região sul do Estado do Tocantins, a $280 \mathrm{~m}$ de altitude, nas coordenadas $11^{\circ} 43^{\prime} 45^{\prime \prime}$ de latitude e $49^{\circ} 04^{\prime} 07^{\prime \prime}$ de longitude.

Segundo a classificação climática de KÖPPEN (1948), o clima regional é do tipo B1wA'a' úmido com moderada deficiência hídrica. A temperatura média anual é de $29,5^{\circ} \mathrm{C}$, com precipitação anual de $1804 \mathrm{~mm}$.

O experimento foi conduzido em delineamento de blocos casualizados, com três níveis de luminosidade (tratamentos), com 15 plantas em cada tratamento, sendo que cada planta constituía uma repetição. Durante as avaliações as mudas foram alocadas eqüidistantes a 0,4 metros.

$\mathrm{Na}$ região de Gurupi-TO, as sementes de Tabebuia heptaphyilla (Vell.) Tol, foram coletadas em matrizes selecionadas quanto à sanidade vegetal, após terem caído pelo menos 30\% do volume de sementes produzidas. As sementes foram coletadas no período de agosto a setembro do ano de 2005. Após a coleta as sementes passaram por um protocolo de assepsia, onde foram levadas ao Laboratório de Sementes da UFT/CAUG, e submetida a um processo de expurgo com o produto comercial Fermag (fosfeto de magnésio), na recomendação de uma pastilha por um período de 48 horas.

Todas as sementes foram colocadas para germinar em canteiros contendo areia lavada, localizado em viveiro com $50 \%$ de sombreamento. Após germinarem e atingirem o estádio de um par de folhas, as plântulas foram transplantadas para sacos de polietileno com $0,28 \mathrm{~m}$ de altura e $0,15 \mathrm{~m}$ de diâmetro, contendo aproximadamente 2 litros de substrato orgânico (composto orgânico 2:1: 1, sendo 2: terra preta, 1: palha de arroz carbonizada e 1: ingesta bovina do rúmem).

A composição química do substrato utilizado no desenvolvimento das plântulas foi: $\mathrm{pH}\left(\mathrm{CaCl}_{2}\right)$ - 5,2; Matéria Orgânica - 4,7\% ; Cálcio - 3,25 $\mathrm{cmol} \mathrm{dm}^{-3}$; Magnésio $4,28 \mathrm{cmol} \mathrm{dm}^{-3}$; Alumínio- 0,39 $\mathrm{cmol} \mathrm{dm}^{-3}$; Hidrogênio+ Alumínio- 3,67 $\mathrm{cmol} \mathrm{dm}^{-3}$; Potássio- $39,1 \mathrm{mg} \mathrm{kg}^{-1}$; Fósforo $-14,8 \mathrm{mg} \mathrm{kg}^{-1}$.

Cinqüenta dias, após a emergência, as mudas de Ipê foram submetidas a três tratamentos de luminosidade, sendo, $100 \%$ de luminosidade (pleno sol), 50\% de Luminosidade (Sombrite) e Sombra Natural. No tratamento com sombra natural, as mudas foram colocadas sob uma área remanescente de vegetação nativa de cerrado stricto sensu, enquanto o nível de $50 \%$ de luz foi obtido com tela de polietileno de coloração preta.

As avaliações de altura da planta e diâmetro do colo foram iniciadas após dez dias de aclimatação, sendo os dados coletados no intervalo de 21 dias, nos seguintes períodos: 60, 82, 103, 124 e 145 dias após a emergência (DAE).

Os parâmetros avaliados foram: Teores de clorofila $a$ (TCA), Teores de clorofila $b$ (TCB), relação clorofila $a / b$, e Teores de clorofila total em folhas de posição superior (TCTs), em folhas de posição mediana (TCTm), e inferior (TCTi), Altura da Planta (AP), Diâmetro de Colo (DC), Massa Seca de Folhas (MSF), Massa Seca de Caule (MSC), Massa Seca de Raízes (MSR) e Massa Seca Total (MST), Área Foliar (AF), Área Foliar Específica (AFE) e a Relação raiz:parte aérea.

Para avaliação de altura da planta e diâmetro do colo, foram medidas todas as mudas. Para as avaliações de massa seca de folhas, caule e raízes, teores de clorofila (a, b e Total), foram 
considerados $35 \%$ das plantas de cada tratamento, tomadas aleatoriamente mediante sorteio no final do experimento. A altura da planta foi considerada desde o colo até o ápice de cada planta e o diâmetro do colo tomado a $1 \mathrm{~cm}$ do solo.

Para a determinação do teor de clorofila foram retiradas três folhas completamente expandidas, localizadas na parte superior, mediana e inferior da planta, que foram imediatamente acondicionadas em papel alumínio e colocadas em caixa de isopor com gelo. Para a obtenção dos resultados de clorofila, retirou-se uma amostra de $100 \mathrm{mg}$ de folha, os quais foram colocados em frasco escuro contendo $20 \mathrm{ml}$ de acetona a $80 \%$. Em ambiente de luz verde, os pigmentos foram extraídos dos tecidos foliares por maceração em almofariz, adicionandose $10 \mathrm{mg}$ de carbonato de cálcio, por amostra. Após maceração e filtragem, o papel filtro foi lavado com acetona a $80 \%$ e o volume ajustado em um balão volumétrico de $25 \mathrm{ml}$. As leituras das absorbâncias das amostras e a determinação dos teores dos pigmentos foram analisadas, segundo a metodologia de Lichtenthaler (1987).

Para determinação da massa seca de raízes, caule e folhas, o material foi separado (folhas, caule e raízes), sendo as raízes lavadas com jatos brandos de água, para remoção do substrato. Esta separação foi realizada segundo a metodologia de Moraes Neto et al. (2000). Separadamente o material foi acondicionado em sacos de papel devidamente identificados, os quais foram colocados em estufa com circulação forçada a ar, à aproximadamente $70^{\circ} \mathrm{C}$, durante 72 horas. Após a secagem, o material foi pesado em balança semianalítica.

Os resultados foram submetidos à análise de variância e as médias comparadas pelo teste de Tukey (5\%).

\section{RESULTADOS E DISCUSSÃO}

Plantas cultivadas em ambiente de 50\% de luminosidade apresentaram maior crescimento em altura do que as plantas em pleno sol e sombra natural. Durante todo período de avaliação foi observado que plantas em ambiente de 50\% de luminosidade se sobressaíram especialmente a partir dos 123 dias de avaliação, diferindo estatisticamente dos outros tratamentos (Figura 1). Resultados semelhantes foram observados com castanha do maranhão (Bombacopsis glabra) e canela-batalha (Criptocaria aschersoniana), (Scalon et al, 2003; Almeida et al, 2004).

As plantas expostas em ambiente de sombra natural apresentaram menores alturas e um incremento pouco expressivo ao longo do tempo (Figura 1), provavelmente em função da falta de fotoassimilados disponíveis para o seu crescimento, já que sob sombra natural a taxa fotossintética deveria ser muito baixa em relação às plantas cultivadas nos ambientes com maior disponibilidade de luz (Taiz e Zieger, 2002).
De acordo com Thompson et al. (1992), nas plantas sob sombra intensa, há a tendência das espécies intolerantes ao sombreamento, principalmente com baixa reserva de carboidratos na semente, pararem o seu crescimento, enquanto que as tolerantes, quando estabelecidas sob sombra intensa, tendem a apresentar um crescimento lento, que se acelera quando uma nova clareira é aberta.

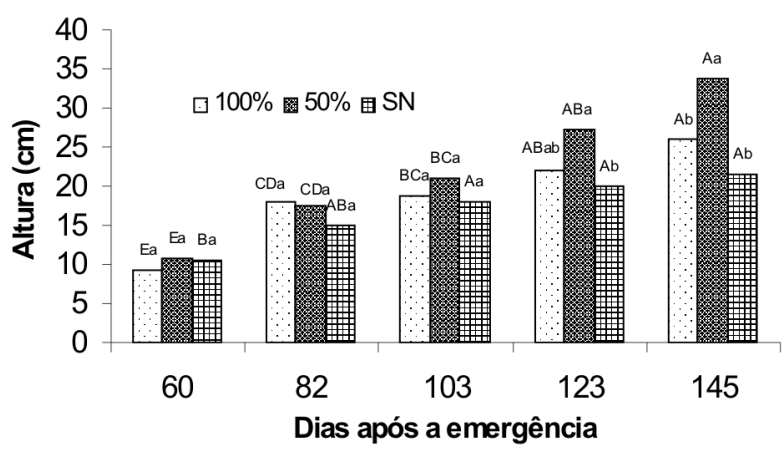

Figura 1 - Altura de plantas de Tabebuia heptaphyilla (Vell.) Tol. em função de diferentes níveis de luminosidade (100\% RFA, 50\% RFA e Sombra Natural). Gurupi-TO. 2006

Médias seguidas pelas mesmas letras maiúsculas considerando DAE e letras minúsculas considerando os níveis de luz não diferem estatisticamente entre si, a 5\% de probabilidade pelo teste tukey.

Quanto ao diâmetro do colo, foi observada diferença significativa entre os tratamentos a partir dos $103 \mathrm{DAE}$, onde plantas expostas em ambientes de $100 \%$ de luminosidade apresentaram maior diâmetro, não diferindo dos $50 \%$ de luminosidade (Figura 2). A maior quantidade de luz disponível permitiu, provavelmente, uma maior produção de fotoassimilados, que se acumularam no caule das plantas. Resultados semelhantes foram obtidos por Almeida et al. (2005) com a espécie Acacia, sob três níveis de sombreamento.

O diâmetro do colo é uma variável de grande importância na avaliação do potencial da muda para a sobrevivência e crescimento após o plantio no local definitivo (Campos \& Uchida, 2002). Ressalta-se ainda que, as plantas com maior diâmetro apresentam maior tendência à sobrevivência, principalmente pela maior capacidade de formação e de crescimento de novas raízes (Carneiro, 1983).

O diâmetro do colmo das plantas ao longo do tempo não variou entre os tratamentos com 100 e $50 \%$ de luminosidade, sendo que o incremento foi ligeiramente maior nas plantas sob $100 \%$ de luminosidade, o inverso do que ocorreu com a altura destas plantas. A maior disponibilidade de luminosidade permite uma taxa fotossintética mais elevada, logo maior acúmulo de fotoassimilados no caule das plantas (Taiz e Zieger, 2002). 


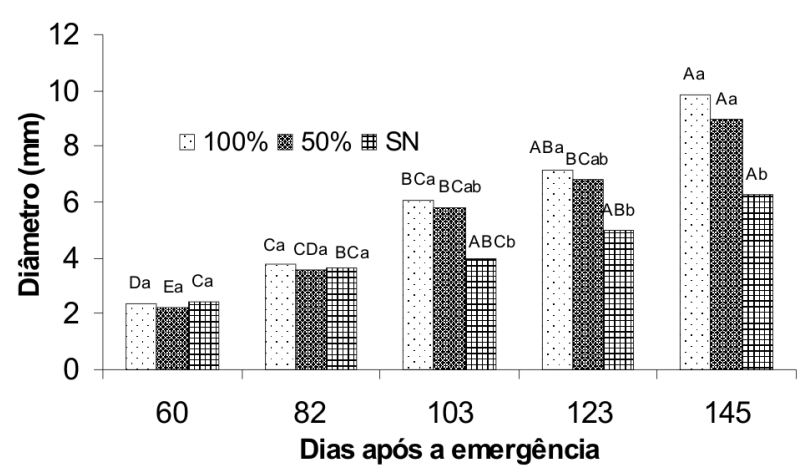

Figura 2 - Diâmetro do colo de plantas de Tabebuia heptaphyilla (Vell.) Tol., em função de níveis de Luminosidade (100\% RFA, 50\% RFA e Sombra Natural). Gurupi-T0, 2006

Médias seguidas pelas mesmas letras maiúsculas considerando DAE e letras minúsculas considerando os níveis de luz não diferem estatisticamente entre si, a 5\% de probabilidade pelo teste tukey.

A área foliar não apresentou diferença significativa entre os tratamentos, porém houve uma tendência dos valores serem maiores no tratamento com $50 \%$ de luminosidade e sombra natural (Tabela 1). O aumento da área foliar da planta mostra a habilidade da espécie em utilizar a radiação fotossinteticamente ativa e alocar os fotoassimilados em resposta a um ambiente particular de luminosidade (Larcher, 2000). Resultados semelhantes foram encontrados por Moraes Neto et al. (2000) para as espécies Guazuma ulmifolia e Peltrophorum dubium.

A luminosidade ocasionou diferença no acúmulo de massa seca total da planta de Tabebuia heptaphyilla, onde foi observado que a condição de $50 \%$ de luminosidade apresentou tendência de maior acúmulo de biomassa total, seguido da condição de $100 \%$, diferindo estatisticamente apenas das plantas expostas em ambiente sob sombra natural (Tabela 1). Em Muntingia calabura, Castro et al. (1996) encontraram também o mesmo tipo de resposta para mudas cultivadas em condições sombreadas. Em razão de não ocorrer diferença entre a condição de $100 \%$ e $50 \%$ de luminosidade, do ponto de vista operacional, plantas a pleno sol, podem ser mais

Tabela 1: Valores de Massa Seca Total (MST), Área Foliar (AF), Área Foliar Específica (AFE), Relação Raiz/Parte Aérea e Peso de Massa Seca das partes das plantas de Tabebuia heptapylla, em função dos níveis de luminosidade (100\% RFA, 50\% RFA e Sombra Natural), aos 145 dias de idade

\begin{tabular}{lllllllll}
\hline Luminosidade & A F & \multicolumn{2}{l}{$\begin{array}{l}\text { Peso de Matéria } \\
\text { Seca }(\mathrm{g})\end{array}$} & $\begin{array}{l}\text { Raiz/ } \\
\text { P. }\end{array}$ & A FE & MST \\
\hline & $\mathrm{cm}^{2}$ & Raiz & Caule & Folhas & Aérea & $\left(\mathrm{cm}^{2} / \mathrm{g}\right)$ & $(\mathrm{g})$ \\
$100 \%$ & $479,67 \mathrm{a}$ & $6,71 \mathrm{a}$ & $2,87 \mathrm{ab}$ & $6,02 \mathrm{a}$ & $0,76 \mathrm{a}$ & $80,55 \mathrm{~b}$ & $15,60 \mathrm{a}$ \\
$50 \%$ & $615,9 \mathrm{a}$ & $6,48 \mathrm{a}$ & $3,55 \mathrm{a}$ & $5,93 \mathrm{a}$ & $0,68 \mathrm{a}$ & $104,58 \mathrm{~b}$ & $15,96 \mathrm{a}$ \\
$\mathrm{SN}$ & $562,01 \mathrm{a}$ & $2,25 \mathrm{~b}$ & $1,62 \mathrm{~b}$ & $2,47 \mathrm{~b}$ & $0,55 \mathrm{~b}$ & $234,51 \mathrm{a}$ & $6,34 \mathrm{~b}$ \\
\hline
\end{tabular}

Valores seguidos por uma mesma letra, na coluna, não diferem estatisticamente entre si, pelo Teste de Tukey, ao nível de $5 \%$ de probabilidade. viáveis economicamente, devido à diminuição de custos com instalações, principalmente de viveiros para produção das mudas.

Plantas submetidas aos ambientes de pleno sol e $50 \%$ de luz apresentaram maior peso de massa seca de raiz (Tabela 1). O maior valor de massa seca de folhas foi observado nas plantas em pleno sol e com 50\% de luz diferindo das plantas mantidas sob sombra natural. Como as plantas tendem a aumentar a fotossíntese sob maior disponibilidade de luz, ocorreu um incremento no teor de carboidratos nas folhas, que influenciou na elevação da massa seca. As plantas sob baixa luminosidade tendem a expandir o limbo foliar, aumentando a área de captação de luz (Larcher, 2000), sem, no entanto, aumentar a massa seca. Como pode ser confirmado pelos dados da área foliar específica, os quais foram maiores na condição de sombra natural (Tabela 1). Resultados semelhantes foram encontrados em duas espécies de carvalho sob duas condições de luminosidade, apresentando melhor desempenho as plantas a pleno sol em termos de matéria seca total, de raízes, caules e folhas (Ke \& Werger, 1999).

A relação raiz/parte aérea não apresentou diferença significativa entre os níveis de luminosidade $(100 \%$ e $50 \%$ ), diferenciando apenas da condição de sombra natural (Tabela 1). A relação raiz/parte aérea mais elevada em plantas de ambientes iluminados indica maior alocação de fotoassimilados no sistema radicular. Segundo Carvalho et al. (2006) essa é uma tendência que permite maior absorção de água e nutrientes, sendo estratégia da planta para garantir maior capacidade de suportar as maiores taxas de fotossíntese e transpiração em ambientes mais iluminados. Assim, foi observado que no ambiente de sombra natural em função da menor taxa fotossintética ocorreu uma redução na quantidade de fotoassimilados translocados para a formação do sistema radicular e do caule da planta (Tabela 1).

Tabela 2: Teores de clorofila a, b, a/b e Total, em plantas de Tabebuia heptaphyilla., em três níveis de Luminosidade (100\% RFA, 50\% RFA e Sombra Natural), Gurupi-TO. 2006

\begin{tabular}{lllll}
\hline Luminosidade & Clorofila a & Clorofila b & a/b & Clorofila total \\
\hline $100 \%$ & $0,57 b$ & $0,91 b$ & $0,62 \mathrm{a}$ & $2,03 \mathrm{~b}$ \\
$50 \%$ & $0,72 \mathrm{~b}$ & $1,45 \mathrm{~b}$ & $0,49 \mathrm{~b}$ & $2,64 \mathrm{~b}$ \\
$\mathrm{SN}$ & $1,38 \mathrm{a}$ & $3,87 \mathrm{a}$ & $0,35 \mathrm{~b}$ & $5,26 \mathrm{a}$ \\
\hline
\end{tabular}

Valores seguidos por uma mesma letra, na coluna, não diferem estatisticamente entre si, pelo Teste de Tukey, ao nível de $5 \%$ de probabilidade.

Os teores de clorofila a, b e total, não variaram dentro dos níveis de $100 \%$ e $50 \%$ de luminosidade, diferindo estatisticamente apenas para o tratamento de Sombra Natural, onde foi observada maior concentração de clorofila (Tabela 2). Nesta condição, a baixa disponibilidade luminosa, fez com que as plantas apresentassem maior concentração de clorofila 
Tabela 3: Teores de clorofila a, b, a/b e Total em (mg g-1 de MS), em plantas de Tabebuia heptaphyilla (Vell.) Tol., em três posições das folha na planta, em função de níveis de luminosidade. Gurupi-T0, 2006

\begin{tabular}{|c|c|c|c|c|c|}
\hline \multirow{2}{*}{ Folha } & \multirow{2}{*}{ Luminosidade } & \multicolumn{4}{|c|}{ Teores de Clorofila } \\
\hline & & a & $b$ & $a / b$ & total \\
\hline & SN & $2,42 \mathrm{Aa}$ & 6,34Aa & $0,37 \mathrm{Ab}$ & 8,78Аa \\
\hline \multirow[t]{3}{*}{ Superior } & $50 \%$ & $1,13 \mathrm{Aa}$ & $3,17 \mathrm{Ab}$ & $0,35 \mathrm{Ab}$ & $4,31 \mathrm{Ab}$ \\
\hline & $100 \%$ & $1,01 \mathrm{Aa}$ & $1,98 \mathrm{Ab}$ & $0,51 \mathrm{Aa}$ & $3 A b$ \\
\hline & SN & $3,42 \mathrm{Aa}$ & $9,44 \mathrm{Aa}$ & $0,36 \mathrm{Aa}$ & $12,88 \mathrm{Aa}$ \\
\hline \multirow[t]{3}{*}{ Mediana } & $50 \%$ & $0,99 \mathrm{Aa}$ & $2,5 \mathrm{Ab}$ & $0,39 \mathrm{Aa}$ & $3,49 A b$ \\
\hline & $100 \%$ & $0,57 \mathrm{Aa}$ & $1,77 A b$ & $0,31 \mathrm{Ba}$ & $2,36 \mathrm{Ab}$ \\
\hline & SN & $1,76 \mathrm{Aa}$ & $5,21 \mathrm{Aa}$ & $0,32 \mathrm{Aa}$ & $7,08 \mathrm{Aa}$ \\
\hline \multirow[t]{2}{*}{ Inferior } & $50 \%$ & $0,98 \mathrm{Aa}$ & $2,76 \mathrm{Ab}$ & $0,38 \mathrm{Aa}$ & $3,75 \mathrm{Ab}$ \\
\hline & $100 \%$ & $0,63 \mathrm{Aa}$ & $1,78 \mathrm{Ab}$ & $0,34 \mathrm{Ba}$ & $2,41 \mathrm{Ab}$ \\
\hline
\end{tabular}

Médias seguidas pelas mesmas letras maiúsculas considerando posição da folha e letras minúsculas considerando os niveis de luz não diferem estatisticamente entre si, a $5 \%$ de probabilidade pelo teste tukey.

(Tabela 2), pois as plantas sob sombreamento natural tendem a aumentar a sua eficiência na captação de luz, aumentando o conteúdo de clorofila (Larcher, 2000). Almeida et al (2004) encontraram resultados semelhantes, onde verificaram queda acentuada no teor de clorofila foliar total em plantas expostas a pleno sol e $50 \%$ de sombra.

Os maiores valores de clorofila $b$ foram encontrados no tratamento de sombra natural (Tabela 2). O aumento, à medida que a radiação se torna menos intensa, é uma característica importante, porque a clorofila $b$ capta energia de outros comprimentos de onda e as transfere para clorofila $a$, que atua intrinsecamente nas reaçôes fotoquímicas da fotossíntese e representa um mecanismo de adaptação à condição de menor intensidade de luz (Scalon et al, 2003).

Os teores de clorofila $\mathrm{a}$, b e total não diferiram estatisticamente entre as posições das folhas na planta, já a relação clorofila a/b foi menor na porção mediana e inferior das plantas cultivadas em 100\% de luminosidade (Tabela 3). Este resultado pode ser conseqüência da redução do teor de clorofila a nesta condição. Na condição de sombra natural o teor de clorofila total é maior nas três posiçôes da planta, esta pode estar relacionada à maior concentração de clorofila b (Tabela 3). O acúmulo de clorofila nos níveis de menor luminosidade pode ser devido à compensação da espécie a baixa quantidade de radiação disponível (Almeida et al, 2005).

\section{CONCLUSÃO}

$\mathrm{O}$ ambiente de sombra natural não é apropriado para o desenvolvimento das mudas de Tabebuia heptaphyilla (Vell.) Tol.;

O teor de clorofila total nas plantas foi maior no ambiente de sombra natural;

O crescimento das plantas foi semelhante no ambiente de 50 e $100 \%$ de luminosidade;
A condição de $100 \%$ de luminosidade pode ser utilizada para a produção de mudas.

\section{REFERÊNCIAS BIBLIOGRÁFICAS}

Almeida, L. P. et al., 2004. Crescimento inicial de cryptocaria aschersoniana Mez. Submetida a níveis de radiação solar. Ciência Rural, Santa Maria, v.34, n.1.

Almeida, S.M.Z. et al., 2005. Alterações morfológicas e alocaçao de biomassa em plantas jovens de espécies florestais sob diferentes condiçōes de sombreamento. Ciência Rural, Santa Maria, v.35, n.1, p.62-68.

Campos, M.A.S.; Uchida, T. 2002. Influência do sombreamento no crescimento de mudas de três espécies amazônicas. Pesquisa Agropecuária Brasileira, v.37, n.3, p. 281-288.

Carneiro, J.G.A. 1983. Influência dos fatores ambientais e das técnicas de produção sobre o desenvolvimento de mudas florestais e a importância dos parâmetros que definem sua qualidade. In: SIMPÓSIO SOBRE FLORESTAS PLANTADAS NOS NEOTRÓPICOS COMO FONTE DE ENERGIA, 1983, Viçosa. Anais... Viçosa: Universidade Federal de Viçosa. p.1024.

Carvalho, N. O. S. et al., 2006. Crescimento inicial de plantas de licuri (Syagrus coronata (Mart.) Becc.) em diferentes níveis de luminosidade. Revista Árvore, v.30, n. 3.

Castro, E.M. et al., 1996. Crescimento e distribuição de matéria seca de mudas de calabura (Muntingia calabura L.) submetidas a três diferentes níveis de irradiância. Ciência e Agrotecnologia, Lavras, v.20, n.3, p.357-365.

Dias-filho, M.B. 1997. Physiological response of Solanum crinitum Lam. to contrasting light enviroments. Pesquisa Agropecuária Brasileira, Brasília, v.32, n.8, p.789-796.

Ke, G.; Werger, M.J.A. 1999. Different responses to shade of evergreen and deciduous oak seedlings and the effect on acorn size. Acta Oecologica. Berlin, v. 20, n. 6, p.579-586.

Larcher, W. 2000. Ecofisiologia Vegetal: São Carlos, RIMA. 531p. 
Lichtenthaler, H.K. 1987. Chlorophylls and carotenoids: pigment photosynthetic biomembranes. Methods Enzymol., San Diego, v.148, p. 362-385.

Lorenzi, H. 2000. Árvores Brasileiras: Manual de identificação e cultivo de plantas arbóreas nativas do Brasil. Nova Odessa: $3^{\circ}$ Edição, São Paulo,

Martins, S. V. 2001. Recuperação de matas ciliares. Ed. Aprenda Fácil, Viçosa. 143pp.

Morais Neto, S.P. et al., 2000. Crescimento de mudas de algumas espécies arbóreas que ocorrem na mata atlântica em função do nível de luminosidade. Revista Árvore, v. 24, n. 1, p 35-45.
Scalon, S. de P.Q. et al., 2003. Crescimento inicial de mudas de Bombacopsis glabra (Pasq.) A. Robins sob condição de sombreamento. Revista Árvore, v.27. n.6.

Taiz, L. \& Zieger, E. Plant Physiology, $3^{\circ}$ ed. Sunderland: Sinauer Associates Inc. 2002, 690p.

Thompson, W.A. et al., 1992. Photosynthetic reponse to light and nutrients in sun-tolerant rainforest trees. II. Leaf gas exchange and component processes of photosynthesis. Australian Journal of Planta Phisyology, East Melbourne, v.19, p.19-42.

Recebido em 24/07/2007

Aceito em 17/03/2008 